\title{
LA SEGURIDAD EN EL ÁMBITO RURAL MAGALLÁNICO EN LA ÉPOCA DE LA COLONIZACIÓN PASTORIL (1880-1910)
}

MATEO MARTINIC B.

\section{RESUMEN}

La vida rural en el territorio continental de Magallanes durante el período del asentamiento colonizador se caracterizó por su relativa tranquilidad, circunstancia que puede atribuirse a la modalidad de ocupación de los campos (grandes espacios) y a una población reducida y desperdigada, bajo un sistema de manejo de la actividad económica (crianza ovina) que facilitó el control de la circulación de personas, pero también a la calidad moral de la gente que se estableció en el ámbito rural, abrumadoramente gente pacífica y laboriosa. En la consideración de la materia se aborda un supuesto fallido intento de asalto al hotel rural de Ciaike a comienzos del siglo XX, en el que la nacionalidad atribuida a los asaltantes conduce a establecer una posible relación con lo efectivamente ocurrido en el ámbito rural occidental de la Patagonia central (Chubut) por la misma época. Sobre tal base se compara lo ocurrido en dos espacios de la frontera patagónica chileno-argentina (central y sur) caracterizados por la intercomunicación de los correspondientes sectores nacionales y se reflexiona acerca de las diferentes situaciones de vida históricamente conocidas y sobre sus posibles causas.

PALABRAS CLAVE: seguridad pública, espacio rural, colonización, Patagonia.

\section{SAFETY IN THE MAGELLANIC RURAL AREA DURING THE PASTORAL COLONIZATION PERIOD (1880-1910)}

\begin{abstract}
Rural life in the Magellan mainland during the colonizing settlement period was characterized by its relative quietness, a fact that can be explained by the land mode of occupation (large areas) and its small population, scattered and dependent of the management system given the economic activity (sheep breeding) that facilitated the control over the movement of people. But also to the moral quality of the people who settled in rural areas, overwhelmingly peaceful and hardworking people. In considering this matter, the news of an alleged failed assault attempt to Ciaike country hotel in the early twentieth century, in which the nationality attributed to the assailants leads to establishing a possible relationship with what
\end{abstract}


actually occurred in the western rural area central Patagonia (Chubut) by the same period, is dealt with. On that basis we compare what happened in two border areas of the Chilean and Argentinian Patagonia (central and south), characterized by the intercommunication of relevant national sectors, and consider the different life situations historically known and there possible causes.

KEY WORDS: public safety, rural areas, colonization, Patagonia.

\section{INTRODUCCIÓN}

Tal como señalábamos en un trabajo reciente $e^{1}$ las características del poblamiento rural en el antiguo Territorio de Magallanes durante el tiempo del establecimiento de la colonización -que para el efecto lo consideramos extendido entre 1880 y 1910-, son insuficientemente conocidas especialmente en lo que se refiere a las circunstancias de la vida cotidiana del común y qué decir en lo tocante a lo referido a la seguridad pública, aspecto este sobre el que la noción disponible es hasta ahora escasa por falta de fuentes que puedan nutrirla. No obstante ello, se cuenta con antecedentes para una descripción aproximada de lo que pudo ser tal situación en la realidad, esto es, algunas noticias y las consideraciones que válidamente puedan hacerse en su respecto.

El proceso colonizador de la vastedad rural sudpatagónica, en la que geográficamente comprendemos al territorio magallánico continental situado al oriente de los Andes y al argentino inmediato desde el río Santa Cruz al sur según pasó a entendérselos desde 1881, pero que en la realidad de un prolongado lapso subsiguiente sólo pudieron diferenciarse por una frontera teórica (Fig. 1), se desarrolló progresivamente teniendo como constante demográfica un bajo y lento nivel de poblamiento, ocupándose un vasto espacio virtualmente deshabitado desde que la población aborigen (aónikenk), nunca numerosa, había declinado drástica y rápidamente desde los años de 1870 hasta quedar reducida a un par de centenares de almas entrado el siglo XX, esto es, una expresión relictual de su existencia milenaria.

El territorio de la Tierra del Fuego (isla grande), igualmente compartido entre Chile y la República Argentina en virtud del Tratado de 1881, queda excluido para el efecto de la consideración de la materia

1 Las Comisarías Rurales del antiguo Territorio de Colonización de Magallanes (1902-1927), Magallania 38(1): 19-35.

Punta Arenas, 2010 por dos razones: una, porque su ocupación original estuvo motivada por el laboreo minero (aurífero), lo que hizo de la misma un fenómeno de ocurrencia temporal y efímera sin embargo de su repitencia periódica; $y$ dos, porque el poblamiento colonizador propiamente tal, bajo la forma económica de la explotación pastoril se hizo sobre la base de enormes concesiones fundiarias, que quedaron en pocas manos, extendidas sobre un espacio geográfico que desde tiempo inmemorial había sido el solar natural de la etnia sélknam que para 1880 lo habitaba con todo su vigor existencial, vale decir, con una población numerosa y fuerte. Afirma la exclusión, siempre en la consideración de la materia que motiva este estudio, el hecho de que ambas expresiones de presencia foránea generaran situaciones de seguridad pública diferentes y que por tanto fueron solucionadas de distinto modo: la primera acotándosela a los asientos mineros del noroccidente fueguino y controlándosela con la presencia policial motivada por la ocurrencia de hechos delictivos puntuales; y la segunda, con la práctica de una política sistemática de castigo a los indígenas que predaban sobre el ganado de las empresas colonizadoras, cuyas bien conocidas consecuencias contribuyeron a la extinción étnica, con lo que antes que transcurriera la mitad del lapso histórico de que se trata la tranquilidad rural fuera un hecho de general aceptación ${ }^{2}$.

Así precisados el ámbito geográfico y las circunstancias de su poblamiento permanente, cabe ocuparse de la materia que interesa.

\section{CARACTERIZACIÓN DE LA VIDA RURAL DURANTE EL PERÍODO DEL ASENTAMIENTO COLONIZADOR}

Teniendo en consideración la bajísima población paulatinamente establecida según lo requería

2 Cfr. Nuestro estudio "Panorama de la colonización en Tierra del Fuego entre 1881 y 1900", Anales del Instituto de la Patagonia, vol. IV: 5-69. Punta Arenas, 1973. 
el fenómeno colonizador y la vastedad del espacio a ocuparse, no es de extrañar que la vida común en lo tocante a seguridad pública se caracterizara por una tranquilidad ejemplar pues no se sabe de hechos significativos que puedan alterar esa percepción. Tal vez las primeras aunque ocasionales manifestaciones en contrario se dieron en la medida que se multiplicaban los asentamientos pastoriles con la ocurrencia de hechos de abigeato connaturales a la crianza de ganado doméstico. Por cierto, el más conocido de esos en la medida que el recuerdo popular prolongó su vigencia fue el de las fechorías atribuidas a de las que fue efectivamente autor Asencio Brunel, un hombre fuera de la ley que cobró notoriedad hacia la segunda mitad de la década de 1880. Individuo escapado de la cárcel de Punta Arenas en la que había sido encerrado por homicidio, consiguió refugiarse por perdidos andurriales de la cordillera viviendo al parecer de la caza y del robo ocasional de caballos a los colonos -animales de gran valor en la época-, práctica que consiguió realizar con éxito pues se dio maña para burlar a sus perseguidores, huyendo, ocultándose y reapareciendo en diferentes lugares para preocupación de la gente común, acontecer que la tradición conservaría con carácter legendario durante largo tiempo dada la mala fama que aquél se ganó entre los pobladores rurales de la Patagonia ${ }^{3}$.

Pero, ciertamente, también hubo otras presencias extrañas en los campos que preocuparon por ese entonces a la escasa población diseminada en ellos y a las autoridades territoriales, como fue el caso de la zona rural oriental del Estrecho próxima a la frontera internacional. Allí algunos forajidos al parecer procedentes del territorio argentino vecino se habían establecido en el área volcánica del sector cuya característica naturales se prestaban para ofrecer refugio a los malvivientes. Esta circunstancia, específicamente, condujo a la creación de un cargo ad hoc, el de Juez-Comisario de la Patagonia, para el que se designó a José Manuel Valdivieso (Decreto 237 de 2 de junio de 1890 de la Gobernación de Magallanes), al que se le encomendó que vigilara por el buen orden de esa región que se hallaba inundada de bandidos que escapan de la Colonia

3 Sobre este personaje se ocuparon varios exploradores y viajeros de la Patagonia del período de entre siglos XIX/ $\mathrm{XX}$. Véase, en particular nuestra obra Patagonia de ayer $y$ de hoy (Ediciones Sociedad Difusora Patagonia Ltda., Punta Arenas 1980).
Argentina de Gallegos, cuidara de los terrenos fiscales y protegiera a los Indios Patagones que se habían ausentado del Territorio Chileno por el mal trato que recibían y que sólo [ahora] principian a volver al él. ${ }^{4}$

Tal disposición, que mostró de inmediato su bondad a juzgar por los resultados conocidos, fue complementada posteriormente con la creación de las Comisarías Rurales (1902) a cuyos titulares se encomendó la vigilancia de la seguridad pública en sus correspondientes distritos jurisdiccionales, con atribuciones particulares para los efectos del control de la vagancia y la prevención del abigeato, además de facultades para expulsar a gente indeseable del territorio nacional.

Acerca del acontecer en el ámbito rural la información documentada es harto escasa, se reitera, procediendo casi en su totalidad de los recuerdos de James Radburne, un inglés que arribó a Magallanes en 1892, territorio en el que permaneció hasta promediar la primera década del siglo XX trabajando en faenas rurales (peón, amansador, ovejero, esquilador), cuando un hecho de sangre del que fue testigo acabó metiéndolo en un embrollo con la justicia chilena del que, no obstante su inocencia, no saldría bien librado; tras otros avatares decidió escapar a suelo argentino donde se radicaría hasta su muerte muchos años después convertido en un esforzado poblador en una zona marginal de la Patagonia andina. Sus andanzas y aventuras fueron recogidas más tarde por Herbert Childs, un periodista viajero norteamericano, que preparó con ellas un interesante libro testimonial, El Jimmy, a Patagonian outlaw 5 .

Pues bien, gracias a Radburne disponemos de información sobre el suceder cotidiano en el ámbito rural magallánico (zona centro-oriental) de aquel tiempo, en lo tocante a ocasionales incidencias que se registraban entre la gente de campo comúnmente durante sus frecuentes pasadas por los "boliches" $u$ hoteles rurales donde se hacía un abundante consumo

4 Oficio 55 de 30 de enero de 1890 dirigido al Juez de Primera Instancia de la Colonia de Magallanes (En Gobernación de Magallanes. Libro de Oficios años 1887, 1888, 1889, 1890 y 1891, Archivo Intendencia de Magallanes, Punta Arenas). Editado originalmente en inglés en 1936 por J. B. Lippincot Company Philadelphia \& London, y reeditado en español bajo el título de El Jimmy, Bandido de la Patagonia por Ediciones de la Universidad de Magallanes, Punta Arenas 1997. 
alcohólico. Tal exceso estimulaba la irascibilidad, lo que originaba grescas que podían llegar a asumir proporciones alarmantes en ocasiones. Así, un gesto cualquiera malinterpretado, una mirada torva o una palabra indebida, trampas en el juego, provocaciones o simples desafíos para exhibir superioridad, en particular cuando solían encontrarse británicos -que entonces abundaban en el ámbito laboral rural- y chilenos, circunstancia en la que el distinto origen étnico podía servir de causa suficiente para altercados y enfrentamientos; o disputas por las escasas mujeres libres que podían encontrarse en la inmensidad del campo sudpatagónico ${ }^{6}$, eran algunos de los tantos motivos fútiles de disgusto que acababan en peleas, a veces con consecuencias.

Aunque los trabajadores rurales eran de suyo gente ruda y áspera podían ser considerados más pacíficos que alborotadores, pero se dio repetidamente el caso de que quienes alteraran la tranquilidad pública fueran principalmente los llamados a cautelarla, esto es los policías o gendarmes chilenos o argentinos. Y en este respecto vale la opinión de Radburne:

La mayoría de la policía en la antigua Patagonia [a uno y otro lado de la frontera] era bastante mala. Muchos de los comisarios podían ser coimeados y si el culpable de algún hecho llegaba a tiempo al oficial y le pagaba lo suficiente, quedaba libre, mientras que otro menos capaz de pagar, pero no necesariamente involucrado, podía ser acusado. Muchos de ellos eran brutalmente crueles y la mayoría eran fácilmente intimidados por un hombre fuerte o por el número ${ }^{7}$.

Estos hechos en su repetición silente conformaron una suerte de "rutina" que sirvieron para matizar

6 En este particular son significativas las acertadas reflexiones de Radburne sobre el papel de las mujeres en la Patagonia de la época pionera que se contienen en las páginas 80 y 81 de la edición en castellano de la obra mencionada.

7 En Childs, op. cit. pág. 93. Radburne ejemplifica a estos funcionarios atrabiliarios con la persona de Mateo Gebhard, un austríaco que habiendo desertado de su nave en Punta Arenas y que luego se ganó la vida en oficios rurales, acabó siendo policía en Argentina alcanzando el grado de comisario. Su notoriedad la tuvo cuando cometió algunos abusos en la zona de Ultima Esperanza durante la época en que dicho territorio era disputado entre Chile y Argentina, asunto concluido con el laudo arbitral de 1902. Sin embargo, para la historia, su fama se cimentó desde que organizó y dirigió la Policía Fronteriza del Chubut, por sus atropellos a la gente de campo, en particular a los chilenos, sin importar de qué lado de la frontera se hallaban. la más bien pacífica monotonía de la vida rural magallánica, entendida, se reitera, por la correspondiente al ámbito patagónico continental oriental. La misma debe ser contextualizada para su debida comprensión en un espacio geográfico más amplio como es el fronterizo compartido entre Chile y Argentina en la inmensidad de la Patagonia. Y en este aspecto, precisamente, lo acontecido en el lapso histórico de que se trata en materia de seguridad caracterizaría a la Patagonia austral (Magallanes-Santa Cruz) como un ámbito más tranquilo que el otro espacio andino en la Patagonia central (aproximadamente entre las latitudes $41^{\circ}$ y $47^{\circ} \mathrm{S}$ ) compartido por ambas naciones (territorios de Aysén y Chubut) y que fuera teatro de sucesos de cierta notoriedad que han motivado una serie de estudios e investigaciones por parte de autores argentinos ${ }^{8}$.

Así, con la característica indicada, se fue desarrollando la vida común rural en lo tocante a la seguridad sin mayor variación en la medida que la población crecía por la evolución del proceso colonizador. Las excepciones, que ciertamente las hubo, se dieron con la ocurrencia de ocasionales hechos de sangre que provocaron la atención pública por su obvia connotación y de los que, otra vez, Radburne sería el mejor relator en tanto que testigo abonado de algunos sucesos.

La arbitrariedad parece no haber sido privativa de la policía en la época de que se trata y -como buen territorio de frontera- también podía ser ejercida por los propios funcionarios de la justicia. Fue lo que aconteció, siempre en el relato de Radburne, cuando tras un homicidio cometido por un chileno de nombre Teófilo en la toldería del jefe aónikenk Mulato en El Zurdo, cuya víctima fue Luis Carminatti, un mestizo ítalo-aónikenk, que era muy amigo del inglés, este, que había sido testigo del hecho se ofreció al jefe indígena para ir a Punta Arenas, poblado al que había huido el hechor, para dar cuenta a la policía del suceso y obtener su apresamiento y juicio. No contaba Radburne con que el tal Teófilo tuviera buena amistad con los policías y así, en vez de conseguir su propósito justiciero acabó malquistado con la autoridad, de resultas de lo cual el inglés fue encerrado en la cárcel sin motivo aparente para ello. De su experiencia en ese

8 Entre otros Alejandro Aguado, Ernesto Maggiori y especialmente Marcelo Gavirati (ver fuentes de consulta al final de este artículo). 
sórdido lugar quedaría para la historia un relato tan veraz como sabroso y que, de paso, permite saber acerca de la forma en que se ejercía la justicia con respecto a la gente común en aquellos tiempos. Escapado de la cárcel y perseguidos por los agentes policiales Radburne llegó hasta la toldería de Mulato, refugiándose entre sus amigos indios que le dieron amparo y lo ocultaron de sus perseguidores. Allí, otra vez, se vio involucrado en un entrevero entre peones chilenos y argentinos que concluyó con un homicidio, circunstancia infortunada que le significó ser acusado de asesinato, imputación que agravó su situación obligándole a huir hacia el inmediato suelo argentino para evitar caer en manos de la justicia chilena, llevando consigo la inmerecida fama de un auténtico malhechor que le ganaría el remoquete de "Bandido de la Patagonia". El relato de sus aventuras recogido por Childs permite conocer acerca del acontecer cotidiano rural, donde los "tipos duros", como los calificara Radburne, solían ser los protagonistas de sucesos violentos que podían alcanzar alguna notoriedad.

Pero, sin embargo de la ocasional ocurrencia de sucesos del género policial, puede afirmarse que las condiciones de la seguridad pública rural en Magallanes en el período comprendido entre el fin del siglo XIX y los principios del XX eran harto satisfactorias, esto es, no constituían mayor motivo de preocupación tanto para las autoridades como para la población mayoritaria sino abrumadoramente conformada por gente de orden y tranquilo vivir. Sirva como prueba lo que escribía el diario El Comercio de Punta Arenas en su edición del día 23 de febrero de 1905 al comentar la llegada del nuevo Jefe de Policía, del que se esperaba la formación -reorganización en verdad-, de un cuerpo de seguridad que respondiera a las necesidades del Territorio de Magallanes, circunstancia que afectaba especialmente a las Comisarías Rurales que se hallaban para entonces desprovistas de personal (agentes policiales).

La población de Magallanes posee condiciones de orden i de moralidad que es difícil observar en la mayoría de las provincias del norte, en donde el desarrollo de la criminalidad ha llegado a un grado alarmante, si hemos de juzgarlo por las crónicas de los diarios de allá, que vienen siempre nutridas de relatos de atentados contra la vida i la propiedad.
Hasta la fecha, por fortuna, aquí son desconocidos los asaltos consumados en los campos por partidas organizadas de forajidos que hacen si no imposible por lo menos peligrosísima, en algunas provincias del Sur o de la frontera, la permanencia de los propietarios rurales en sus fundos o haciendas, en los cuales tienen que vivir de continuo sobresalto i con el arma al brazo para defenderse de los bandidos. ${ }^{9}$

Contribuían a tan satisfactoria situación, a juicio del articulista, tanto la calidad moral de la gente que aquí habitaba, cuanto la certidumbre de encontrar ocupación para quien la requiriera; las características del clima riguroso y el aislamiento geográfico de Magallanes, circunstancias que de hecho dificultaban el arribo y el actuar de la gente de mal vivir.

No obstante tal realidad importaba que la reorganización que se deseaba para el cuerpo policial contemplara el personal necesario para proveer los requerimientos de vigilancia rural, carencias que amparaban la ocurrencia ocasional de hechos delictuales, como se reconocería en información posterior del mismo año, que daba cuenta del hecho que [...] los extensos campos limítrofes con la Argentina necesitan cierto preferente resguardo a fin de impedir las fechorías que suelen en ellos cometerse, quedando sus autores casi siempre impunes $^{10}$.

A propósito, cabe aquí una comparación sobre la seguridad pública en los dos espacios geográficos patagónicos compartidos por Chile y Argentina, para caracterizar con alguna aproximación las situaciones que se dieron en ambos a lo largo del tiempo y diferenciarlos en consecuencia.

Los antecedentes de que se dispone demuestran que el espacio fronterizo central (Aysén oriental/sudoeste de Río Negro/oeste del Chubut/ noroeste de Santa Cruz) fue lejos un ámbito signado por la inseguridad, donde la criminalidad tuvo

9 Artículo titulado "Policía de Magallanes. En vías de mejoramiento", edición citada. Téngase presente que la palabra "Frontera" no debe entenderse en el sentido común del concepto (límite internacional), sino, en este caso, como referencia a la entonces (y todavía hoy) denominada "La Frontera" para singularizar geográficamente al territorio mapuche incorporado a partir de 1881.

10 Información titulada "Gendarmes para Magallanes", El Comercio de Punta Arenas, edición del 16 de diciembre 1905. 
temprana data y prolongada vigencia, en tanto que el espacio fronterizo austral (Magallanes centro oriental/sudoeste y sur de Santa Cruz) conformó un ámbito donde la tranquilidad rural constituyó la norma y las acciones delictuales fueron acotadas en el tiempo y de escasa relevancia.

Respecto del primero tanta fue su importancia y vigencia que el ingeniero José M. Pomar cuando realizó durante 1920 su conocido viaje de inspección por el sector central del Territorio de Aysén, creyó necesario consignarlo para la debida información de las autoridades nacionales chilenas en su posterior relación del mismo:

[...] en la zona limítrofe, sobre todo al lado argentino, la criminalidad asume caracteres alarmantes. Durante el año 1919 ocurrieron desde el lago Fontana al río Huemules, comprendiendo la zona del lago Sarmiento, Río Mayo, Arroyo Verde y Costa del Senguer, 47 hechos de sangre, cuyo autores en un 50\% han quedado impunes. En la primera quincena de enero de 1920 se produjeron 11 homicidios de cuyos autores 5 fueron aprehendidos y los restantes eran prófugos ("El Rivadavia", Comodoro Rivadavia, 24-IV-1920). Sólo el 5-1-1920, fueron asesinados cerca del río Guenguel los 3 estancieros Mc-Leod, González y Marchantén, los que con un albañil venían con dinero en un automóvil desde Comodoro Rivadavia, y estaban detenidos abriendo una puerta premeditadamente amarrada con alambres; de este crimen fue culpado entre otros Eleuterio Iribarne (alias "el papas crudas"), bolichero en Balmaceda. La policía fronteriza argentina al perseguir a los culpables, en una campaña de dos meses y medio hasta el 10 de abril, dejó a su paso como en otros tiempos en el lado chileno una protesta general por sus robos, estafas, violaciones de mujeres y apaleaduras de pobladores del Chubut. Después de esto el comisario Germán García fue preso, los comisarios Gustavo Sotuyo e Inocencio F. Varela se fugaron en Madryn cuando iban a comparecer ante el juez letrado, y el jefe de la policía fronteriza D. Eduardo A. Cerri fue suspendido ("la República", Comodoro Rivadavia, 1-V-1920). Cerri fue el sucesor del mayor D. Mateo Gebhard, austríaco, que se hizo tristemente célebre por apalear chilenos en la Patagonia. ${ }^{11}$

11 La concesión del Aisén y el valle Simpson (Santiago, 1923), págs. 94 y 95.
En verdad, el ámbito fronterizo de que se trata, en particular el occidente chubutense y el sudoeste ríonegrino ya habían cobrado fama respecto de la materia desde tres lustros antes, cuando allí se establecieron algunos forajidos norteamericanos que realizaron algunas fechorías con inmediata repercusión en la prensa argentina y cuyos pormenores y circunstancias han sido materia de investigaciones y estudios históricos en época reciente.

En efecto, según reza el expediente judicial motivado por sus tropelías [...] por distintos puntos y fechas desde el año 1902 llegaron a este Territorio y se establecieron en Cholila y Esquel como honrados trabajadores los sujetos Enrique Place ó Ed. Jones ó Harry Longabaugh o Sun Dance Kid, jefe de una gavilla de los Estados Unidos de América, su mujer Ethel ó Mari Place; Santiago Ryan o James P. Ryan ó George Parker ó Patricio Cassidy, domiciliándose en Cholila como estancieros; Andrés Duffy ó Doffy ó Harvey Logan (á) "Dientes de Oro"; Robert ó Bob Evans ó Hood Place; William ó Guillermo Wilson; Peter Litjens, Alen Garned y un sujeto apellidado Grice...12. Algunos en este conjunto, con nutrido historial policial en su país de origen, Estados Unidos de América, habían ganado mala fama en el territorio occidental (Far West) como integrantes de la banda Wild Bunch (Kid, Cassidy y Logan) con asaltos, robos y asesinatos cometidos entre las postrimerías del siglo XIX y los años iniciales del XX, sin que las autoridades y fuerzas policiales consiguieran echarles mano. Disuelta la gavilla y dispersos sus miembros componentes, algunos de ellos, Robert Leroy Parker, alias Butch Cassidy, Harry A. Longabaugh, alias Sundance Kid, y Ethel Place, la buenamoza mujer de la banda, decidieron en 1901 abandonar su país para escapar del rastreo que de ellos y otros delincuentes del grupo hacía por entonces la afamada Agencia de Detectives Pinkerton. El destino elegido fue Sudamérica, concretamente el puerto argentino de Buenos Aires, hasta el que cada año arribaban millares de emigrantes procedentes de Europa circunstancia que había de permitirles pasar inadvertidos como unos de tantos que anhelaban dar comienzo a nuevas vidas. Una vez allí (o antes

12 Fojas 147 y 147 vuelta del expediente judicial de 1911, citado por Marcelo Gavirati en Buscados en la Patagonia. La historia no contada de Butch Cassidy y los bandoleros norteamericanos (Segunda edición ampliada y corregida. La Bitácora Patagónica-Patagonia Sur Libros, Buenos Aires 2005), pág. 9. 
quizá) enterados de la posibilidad de adquirir tierras en la Patagonia andina donde algunos compatriotas se habían instalado previamente como honrados colonos criadores de ganado, se encaminaron hacia el oeste del Chubut, territorio donde efectivamente encontraron terrenos aptos para el pastoreo cuyos derechos de ocupación pudieron obtener tal vez con parte del producto de sus robos de marras. Se instalaron en la zona de Cholila para iniciarse como colonos ganaderos en un ambiente donde, además, su lengua inglesa era común. Otros de sus antiguos compinches los imitarían más tarde.

Si lo que se buscaba, además de poner buena distancia entre ellos y sus rastreadores, era brindar a terceros la imagen aparente de una vida quieta y laboriosa como la de tantos inmigrantes, ciertamente que lo consiguieron, al menos por los primeros tiempos luego de su arribo, tanto que llegaron a ser estimados como buenos vecinos por cuantos habitaban en la cercanía de su establecimiento. La cosa había funcionado y funcionaba bien, sólo que al parecer no había tal "conversión" del bandolerismo a la vida honrada; se trataba de una bien meditada y mejor armada treta para despistar y retornar a las viejas andanzas cuando se dieran las circunstancias ${ }^{13}$.

Estas comenzaron, recomenzaron a decir verdad conocido su historial, hasta dar forma a una secuencia de hechos asaltos y robos- que se les atribuyeron: Telsen y Ñorquinco (1904); Cholila y Río Gallegos (entre fines de 1904 y principios de 1905), y Villa Mercedes (fines de 1905). Luego, tras un lapso de inactividad delictual se produjo el fallido asalto al establecimiento de la firma Lahusen en Comodoro Rivadavia (febrero de 1908), cuya responsabilidad se les endilgó, aunque los que intervinieron fueron Hood-Evans y Perkins. Por ese entonces arribaron a la zona cordillerana del Chubut otros facinerosos norteamericanos: William Wilson, Andrew Duffy y Peter Litjens a los que junto con Hood-Evans se vería comprometidos después en el asalto a la Cooperativa Mercantil de Arroyo Pescado (fines de 1909), hecho delictual que alarmó especialmente a la gente honesta a todo lo ancho y largo de la Patagonia, especialmente por el asesinato de su apreciado gerente, el ingeniero

13 Según Marcelo Gavirati no debería excluirse la posibilidad de un sincero plan de "retiro" delictual que algunas circunstancias habrían impedido prolongar (lealtad o amistad, o el temor de ser delatados por algunos que sabían de sus antiguas andanzas).
Llwyd Ap Iwan. De igual modo los nombrados intervinieron en varios otros robos y actos de violencia contra personas en la zona de Río Pico (mediados de 1910), y en él también afamado secuestro del estanciero Lucio Ramos Otero en el sector de Corcovado, suroeste del Chubut (marzo de 1911), que cerraría, para la historia, la secuencia criminal de los bandidos norteamericanos en la Patagonia ${ }^{14}$.

Este historial en particular, amén de caracterizar la inseguridad del espacio fronterizo chilenoargentino en la Patagonia central, vincularía al mismo con el espacio austral por la ocurrencia del robo a la agencia del Banco de Tarapacá y Argentina de Río Gallegos, suceso que alarmó tanto a la población de la localidad capital de Santa Cruz, como a la chilena de Punta Arenas y a la de todo el ámbito rural centro-oriental magallánico ${ }^{15}$.

Como podía esperarse la prensa puntarenense recogió y comentó la información de lo ocurrido en febrero de 1905 en el vecino suelo argentino, lo que contribuyó a reafirmar localmente la necesidad de disponer de un cuerpo policial eficiente para garantizar la tranquilidad y la seguridad públicas, más todavía en el escasamente poblado ámbito rural, además de instalar en el imaginario colectivo la sensación de que sin embargo de valorarse las mejores condiciones relativas de "orden y moralidad" en la población territorial, Magallanes no estaba libre, dada la fluida e irrestricta relación fronteriza y la facilidad de movilidad entre los sectores nacionales en un área geográfica carente de dificultades naturales para el caso, de la ocurrencia siquiera ocasional de fechorías como la comentada.

Pero un suceso del género policial, supuestamente acaecido en el transcurso de la primera década del siglo XX, sirve como nexo para asociar ambas realidades, la de la Patagonia central andina y la de la Patagonia austral, y para hacer algunas consideraciones en lo que concierne a la materia.

Para una mejor compresión del asunto cabe una referencia a la evolución de la población rural en Magallanes en el período que interesa.

14 Para una más completa información sobre esta materia remitimos al lector a la bien documentada obra de Gavirati mencionada.

15 El historiador Osvaldo Topcić ha hecho una narración pormenorizada del suceso, con algunas reflexiones y conjeturas para su comprensión en el contento patagónico de la época, en su libro Historia de la Provincia de Santa Cruz. Crónicas y Testimonios (Centro de Estudios Históricos "Prof. Carlos S.A. Segreti" Córdoba 2006). 
El primer recuento censal que informa sobre la misma es el de 1885. Para entonces sobre un total de 2.085 habitantes registrados en el Territorio de Magallanes ${ }^{16}$, sólo 585 vivían en el ámbito rural, esto es, fuera del único centro urbanizado que era Punta Arenas, desde la península de Brunswick hasta la frontera con Argentina y desde la precordillera (meridiano $71^{\circ} 30^{\circ}$ Oeste aproximadamente) hasta punta Dungeness en la zona continental; y en la isla grande de Tierra del Fuego.

El censo nacional siguiente, realizado en 1895, registró 5.170 y 1.964 , respectivamente, y el subsiguiente nacional (1907), dio en cada caso 17.330 y 4.631 habitantes. Ello si bien permite conocer el crecimiento poblacional rural intercensal 1885-1907 (86 \%), da cuenta también del subpoblamiento del área correspondiente en comparación con el aumento de la población urbana. Pero, además, si se considera la superficie del territorio entonces ocupado (ecúmene) en el amplio sector oriental que interesa, esto es, aproximadamente $20.000 \mathrm{kms} 2$, se aprecia para el mismo una densidad bajísima de apenas 0,08 habitantes por kilómetro cuadrado.

La información desglosada disponible para el censo nacional de 1907 da cuenta de la siguiente población:

\begin{tabular}{|c|c|c|c|}
\hline \multicolumn{4}{|c|}{ Comarca $2^{\underline{a}}$ Patagonia } \\
\hline Distrito & Cabo Negro & 167 & habitantes \\
\hline “ & Río Verde & 249 & “ \\
\hline “ & Morro Chico & 146 & " \\
\hline “ & Punta del Monte & 160 & " \\
\hline “ & Ciaike & 366 & “ \\
\hline “ & Punta Delgada & 183 & “ \\
\hline \multicolumn{4}{|c|}{ Comarca $4^{\underline{a}}$ Occidente } \\
\hline Distrito & Ultima Esperanza & 392 & habitantes \\
\hline
\end{tabular}

De ese total, 1.317 de los registrados eran varones y únicamente 362 mujeres. En suma una población bajísima con una manifiesta desproporción en la composición sexual.

\section{EL SUPUESTO (Y FALLIDO) ASALTO DEL HOTEL CIAIKE}

Una consulta que nos fuera hecha durante octubre 2011 nos ha permitido imponernos de

16 Únicamente población civilizada. un hecho al parecer ignorado hasta ahora para la historia como fuera el supuesto asalto del hotel rural de Ciaike (Magallanes centro-oriental) en una época indeterminada entre 1907 y 1908.

En efecto, el señor Hugo Jankelevich Wortsman nos solicitó información sobre el antiguo hotel Ciaike, establecimiento que regentara su abuelo Elías Wortsman durante el período mencionado. La consulta versaba sobre un aspecto específico del que no se dispone de mayor información y respecto del cual nos ocupamos hace algunos años en un estudio sobre el ramo mercantil de la hotelería ${ }^{17} y$ para satisfacerla debidamente requerimos mayores antecedentes a nuestro consultante. Así hemos sabido de la actividad comercial del abuelo Wortsman en el lugar, circunstancia que le permitió mantener a su familia y, conjeturamos, hacerse de una situación económica de estabilidad.

Sobre el hotel de Ciaike es poco y nada lo que se conoce. Ubicado en lo que había sido un paradero aónikenk (Sh-aik) sobre la ruta que antaño vinculaba el litoral del estrecho de Magallanes con el valle inferior del río Gallegos (parte del inmenso país estepario que integraba el dominio cinegético de esa etnia) -antecedente inmediato del primer camino tropero practicable por los civilizados antes de la ocupación colonizadora-, fue abierto en simultaneidad con la expansión de dicho proceso por el sector nororiental continental de Magallanes para el servicio de cuantos pasaran por allí por diferentes razones y para los requerimientos de la peonada rural ${ }^{18}$. Así su quehacer era el servicio de

17 La hotelería en el antiguo Magallanes (1870-1950) (Magallania, vol. 33(1): 5-24, Punta Arenas, 2005).

18 Se dispone de dos excelentes descripciones sobre lo que era esta ruta primitiva hacia el tercio final del siglo XIX. La primera conocida la brinda George Ch. Musters que pasó por ella en 1869 con rumbo suroeste-noreste (Vida entre los Patagones, Solar/Hachette. Buenos Aires 1964), y la otra de John B. Hatcher, que transitó con sentido inverso en 1896 (Cazadores de huesos en la Patagonia. Expediciones de la Universidad de Princeton a la Patagonia.Zagier \& Urruty Publications. Buenos Aires 2003). Este último viajero relata su paso por Oshii Aike (Ciaike) sin precisar si allí había o no posada, lugar donde no fue bien atendido por el encargado un italiano al que recordaría en su obra como "un tano de porquería". Para la historia quedaría además su tajante comentario... En cambio de encontrarme con la recepción cálida y hospitalaria que tanto necesitaba, experimenté el único caso de trato descortés que encontré en todos mis viajes por la Patagonia (pág.98). 
comidas y alojamiento para personas, forraje, agua y pesebreras para cabalgaduras, por una parte, y de almacén para la venta de variados artículos necesarios para la gente de campo (incluyendo en primer lugar licores fuertes) y de bodega de acopio para la adquisición de productos de la naturaleza (pieles, plumas de avestruz y, muy excepcionalmente, oro de lavaderos, fruto de algún laboreo ocasional como se dio efectivamente durante el período de entre siglos XIX y XX, época en que la "fiebre aurífera" contagió a medio mundo en Magallanes ${ }^{19}$.

Entendido así, cada uno de los establecimientos del género pudo ser, tal vez, el objetivo en donde desde la perspectiva de un maleante necesariamente debía haber algún botín que interesara, esto es, dinero o valores que robar y de esa manera proceder en consecuencia. Así queremos explicar el intento de asalto de que habría sido objeto el hotel de Ciaike.

Esta situación pudo darse en el caso de que se trata cuando hacia 1902 llegó a Magallanes Elías Wortsman junto con su esposa Dora Toperberg y una hijita, procediendo desde Buenos Aires, puerto al que habían arribado con anterioridad como emigrantes naturales del Imperio Ruso. Buscando en que ocuparse con provecho, el matrimonio optó por el trabajo hotelero siguiendo una tradición familiar que procedía de ambas partes. Fue así que accedieron a la propiedad del hotel de Ciaike, si Wortsman disponía de recursos para adquirirlo o, si no, a su arrendamiento, en cualquier caso para llevar adelante su explotación comercial. Y de ese modo todo debió darse bien, al parecer, como lo demuestra una permanencia en ese apartado lugar extendida hasta 1908. Aquí la familia aumentó con una niña en 1905 y con dos mellizas nacidas en el hotel en $1907^{20}$.

19 Aunque la zona centro-oriental magallánica no estuvo entre los distritos auríferos históricos, en la época de que se trata, algunos buscadores lavaron arenas en los cauces de los ríos Gallegos Chico y Chico o Ciaike. Una actividad más antigua y prolongada del género se dio en la costa del estrecho de Magallanes desde la Primera Angostura hacia el Atlántico donde había depósitos de oro de origen aluvional puesto en evidencia luego del afortunado hallazgo de Zanja a Pique (1884).

20 Inscripciones de nacimiento número 255 y 256 de fecha 25 de mayo de 1907, correspondientes a Caridad y Esperanza Wortsman Toperberg, respectivamente, nacidas el 25 de febrero anterior (Registro de Nacimientos año 1907, Archivo Oficial del Registro Civil, Punta Arenas).
Entre otros antecedentes nuestro consultante brindó la siguiente estupenda noticia: Hay una historia vinculada que dice que en esa zona se dejaban caer cuatreros y asaltantes provenientes del lado argentino entre los cuales una de esas bandas era comandada por una mujer. En ausencia de mi abuelo y bisabuelo se enfrentaron con mi abuela con tres niños pequeños y como ella (mi abuela) hablaba muy poco español y con acento argentino increpó a la asaltante diciéndole que "era el colmo que una compatriota asaltara a una de su propia sangre y todavía con niños pequeños" por lo cual la asaltante (que al parecer era famosa en esa época) le perdonó la vida y no se llevó nada ${ }^{21}$.

Ante tan sorprendente -por excepcionalcuanto desconocida información que nos llevó de inmediato a relacionar a los forajidos protagonistas con la banda de Buth Cassidy, Sundance Kidd y Ethel Place, requerimos a nuestro consultante mayor precisión obteniendo la siguiente respuesta:

Lo de los bandoleros dirigidos por una mujer lo tengo directamente del relato de mi madre. Al parecer eran dos hombres y una mujer. Eran extranjeros (al igual que mis familiares), hablaban español con acento argentino (igual que mi abuela). [...] Cuando fue asaltada se encontraba con sus suegros y con sus hijos chicos, posiblemente con otras hermanas. [...] Los asaltantes deben haber sabido que mi abuelo Elías Wortsman manejaba dinero y oro. Su oficio era comprar oro a los pirquineros que operaban en Río Chico y además compraba lana. Vendía monturas, riendas, mantas y abarrotes a las estancias cercanas. Tenía una gran visión comercial y era muy trabajador por lo que rápidamente se hizo conocido en la zona.

Cuando la jefa de los asaltantes intimidó a mi abuela exigiendo dinero y oro, bajo la amenaza de muerte, ella (mi abuela) no se asustó y por el contrario la increpó: "es una vergüenza que una extranjera que viene de Argentina venga a asaltar a otra extranjera que también viene de Argentina y a otro país (Chile).Tienes que ver que somos solamente mujeres y niños que están llorando. ¿Qué clase de mujer eres?

[...]Ante esta situación, el valor demostrado por mi abuela por defender a sus hijos y bienes, hizo que los ladrones se marcharan sin llevar ab-

21 Comunicación de fecha 4 de noviembre de 2011. 
solutamente nada. Al parecer, ellos habían comido previamente en la posada, lo que naturalmente tampoco le pagaron a mi abuela. [...] Según entendí el relato de mi madre los ladrones andaban a caballo, armados con armas cortas en el cinturón y con escopetas en la montura. Al parecer esto era normal en esa época entre los viajeros y ganaderos básicamente por la gran presencia de pumas en los caminos y estancias ${ }^{22}$.

La precisión requerida si bien interesante pecaba de incompleta al no brindar la fecha del suceso. Conjeturando que el mismo, de haber ocurrido habría sido recogido por la prensa de Punta Arenas en la época, el paso siguiente era obvio, de modo que decidimos revisar en la hemeroteca de la Biblioteca del Instituto de la Patagonia, concretamente las ediciones del diario $\mathrm{El}$ Comercio, uno de los dos más importantes de entre varios que por entonces se publicaban en la capital magallánica. El período comprendido en la revisión fueron los años 1907 y 1908, partiendo de la base de que el hecho debió producirse con posterioridad al nacimiento de las mellizas Wortsman, aunque con holgura temporal como resguardo y hasta el término de 1908 año señalado por nuestro consultante como el de alejamiento de la familia de Ciaike. El resultado de la revisión fue negativo, aunque sirvió para comprobar que en las ediciones tenían acogida aun las noticias menores originadas en el ámbito rural.

Así las cosas, volvimos a solicitar a nuestro amable consultante una información complementaria que ayudara a fechar el suceso de marras. La respuesta obtenida nos ha permitido enterarnos del fallecimiento de su madre (la informante directa) en 1999, a quien sobrevive Una tía de 88 años, que nació en 1923 (Mi abuela falleció en 1945). Esta tía dice que no se acuerda del tema y una prima de 87 años me confirmó que los abuelos vivieron entre 1901 y 1908 en Punta Arenas. También me confirmó sobre el asalto ${ }^{23}$. De este modo la incógnita persiste.

$$
\text { - o - }
$$

Los campos en los que se encontraba el paraje de Ciaike (lote 25) fueron adjudicados en remate en 1905 a Juan Stuven que lo adquirió para The

22 Comunicación con fecha 5 de diciembre de 2011.

23 Comunicación de fecha 23 de enero de 2012. Lo destacado es nuestro.
Patagonian Sheep Farming Company que formó con ellos la estancia homónima y que mantuvo en su dominio hasta la mitad del siglo ${ }^{24}$. Parece ser que el hotel de Ciaike no habría continuado operando mucho más allá de $1910^{25}$. Quizá fuera adquirido por la entidad ganadera propietaria para ser cerrado de inmediato tal como había acontecido con otros antiguos hoteles (Laguna Romero y Pozo de la Reina), en atención a que su actividad no era mirada con simpatía por los estancieros de la vecindad. Sus instalaciones acabarían reutilizadas por la entidad propietaria y posteriormente serían desarmadas. En pocos años el antiguo hotel rural de Ciaike sería apenas un recuerdo para cuantos pasaron a su vera siguiendo la vieja senda indígena.

$$
\text { - O - }
$$

Tornando al punto y en procura de una explicación razonable para el suceso proponemos dos hipótesis: una que acepta el hecho como históricamente real y otra como un supuesto sin otro fundamento que una imprecisa tradición familiar.

En el primer caso y sobre la base de la relación conocida, hay una clara referencia a la habilidad sicológica criminal empleada por los presuntos asaltantes que aparentando ser gente decente y honesta se habría dado maña para extraer información de su hospedera acerca de los valores de los que podrían apropiarse en un golpe de mano, obtenida la cual habría procedido según se ha relatado.

Pero, si tal pudo ser ¿cómo ajustar su ocurrencia temporal con la presencia histórica conocida de los bandoleros norteamericano en Río Gallegos (1905), estando como circunstancia determinante del suceso de Ciaike el hecho de haber varios niños pequeños lo que sólo se dio entrado 1907? Esa es la primera cuestión a resolver en la alternativa que se considera.

La segunda hipótesis se refiere más que a la condición de "extranjeros" de los supuestos asaltantes, cosa que aparecen aceptable por la descripción de

24 En 1950 la estancia "Ciaike" fue vendida a la Sociedad Explotadora de Tierra del Fuego en una operación comercial que incluyó también a la estancia "Kimiri Aike"; ambas fueron incorporadas después como "secciones" de la gran estancia "Punta Delgada".

25 El establecimiento no aparece incluido con patente comercial en el Rol de Avalúos Urbanos y Rural del Territorio de Magallanes Año 1914. 
la informante, a que el trío protagonista estuvo integrado por una mujer. Por la historia se sabe (Gavirati y otros) que la única fémina que formo parte de una banda criminal fue la norteamericana Etta o Ethel Place, pero, es igualmente sabido que en el caso del Banco Tarapacá y Argentina de modo comprobado intervinieron dos sujetos de la misma nacionalidad que no eran ni Butch Cassidy ni Sundance Kidd (compañeros de habituales de aquélla), como podía suponerse sino otros dos miembros de la banda según el historiador Gavirati. Sin embargo de ello, en el asalto de marras quedaron cabos sueltos por atar y uno de ellos se refiere a la presencia de una mujer no identificada. En efecto, al recibir hace unos años la visita del historiador Osvaldo Topcic, este nos insistió en su convicción de que efectivamente una mujer había formado parte del grupo asaltante, aunque sin intervenir directamente en el suceso del que se trata y que ésta era, precisamente, Etta Place, cuya supuesta presencia motivaba su visita a Punta Arenas en procura de alguna información. El fallecido historiador santacruceño seguía la pista de aquélla para afirmar su presencia en Magallanes en la época del asalto. Así, otra vez y aceptando tal posibilidad, surge de inmediato la duda acerca de cómo conciliarla temporalmente con la existencia de la familia Wortsman, integrada por niños que a la sazón eran de corta edad y que vivían con sus padres y abuelos en el hotel de Ciaike. Y ante la duda nos preguntamos si la razón de esta desfase temporal puede deberse a la debilidad del recuerdo familiar por parte de la informante o, si de verdad y aceptando como real el asalto de Ciaike, que en el mismo intervinieron dos hombres y una mujer extranjeros. Y ellos ¿quiénes fueron?

Y si el asalto nunca ocurrió ¿cómo explicar la tradición familiar de los Wortsman vinculada al establecimiento hotelero de campo que administrara o poseyera el abuelo Elías en el paraje rural de Ciaike? Toda tradición, debe aceptarse, tiene un fundamento siquiera lejano de autenticidad, más inclusive que los mitos. ¿Es por tanto aquella que recogemos de esta especie, en cuanto refleja el conocimiento que los abuelos pudieran tener sobre los bandoleros norteamericanos que hicieron fama por sus malandanzas en la Patagonia de principios del siglo XX y, por consecuencia, reflejo también del temor que pudo apoderarse de las poblaciones del vasto ámbito rural ante la posibilidad de ser víctimas de un hecho de violencia que afectara a personas y bienes?

La duda habrá de permanecer mientras no se conozca más informaciones que hagan posible una mejor información y, por ende, una satisfactoria explicación para este, por ahora, supuesto episodio.

\section{LA SEGURIDAD PÚBLICA EN DOS ZONAS DE LA FRONTERA CHILENO- ARGENTINA EN LA PATAGONIA}

Más allá de la posibilidad de ocurrencia del hecho comentado en el apartado precedente, importa abundar sobre las distintas situaciones que se dieron en el transcurso del período histórico de que se trata en los espacios fronterizos del sur y del centro-oeste de la Patagonia.

En éste, según se ha visto, la inseguridad fruto de la violencia criminal conformó la norma desde temprana época y pasó a caracterizar el principio del siglo XX, hasta, aproximadamente, mediados de su tercera década. En aquél, en cambio, la tranquilidad definió la vida de sus habitantes. Acerca de por qué hubo de ser así caben algunas consideraciones preliminares pues, así lo entendemos, sus razones más profundas quizás hayan de encontrarse en la sociología (o en la antropología social) más que en la historia.

Tal vez debió suceder de la manera conocida por la calidad de los correspondientes habitantes -conjetura que formulamos conscientes del riesgo que implica hacerlo-, pues en el caso del espacio fronterizo patagónico centro-occidental si su poblamiento inicial se realizó con pobladores de origen galés procedentes del valle inferior del río Chubut, esto es, con gente de suyo de paz, fe religiosa y trabajo, con posterioridad se incorporaron tanto del lado argentino como del chileno otros elementos cuyas características morales tal vez no se ajustaron al paradigma galés, lo que no significa que necesariamente fuera gente reprochable pues entre ellos debió haber una mayoría de personas ordenadas y pacíficas. Pero en algún momento, por razones que bien valdría conocer, la tranquilidad de la vida rural comenzó a ser perturbada con la irrupción de la violencia criminal que demoraría en ser eliminada.

En el sur, está claro, las cosas se dieron de distinta manera, pues quienes poblaron tanto en los espacios urbanos como en el ámbito rural sin embargo de proceder de diferentes orígenes étnicos y 
culturales (distintos países europeos, centro de Chile y Chiloé), en su abrumadora mayoría fueron también gente pacífica y laboriosa, moralmente ordenada -en especial los europeos- y con diferentes niveles de instrucción escolar, que como denominador común poseía el anhelo de trabajar duro y honestamente para hacerse de una situación personal y familiar que permitiera el arraigo definitivo y una existencia ulterior que estuviera garantizada por una progresiva mejor calidad de vida. Así, ni la plurietnicidad ni la multiculturalidad fueron obstáculos para una convivencia de progresiva y armónica interrelación e integración que acabaría en saludable fusión, fundamento apropiado para el buen desarrollo de las respectivas sociedades magallánica y santacruceña.

El contexto económico latifundario tipificó la vida rural en el transcurso de la primera década del siglo XX hasta 1910, o, lo que es igual, hasta la conclusión del proceso de la colonización (en otros términos hasta el acotamiento espacial de la frontera ovina) y, por tanto, la forma de explotación productiva, esta entendida como normadora de tecnología, de formas de trabajo y de hábitos de vida.

De ese modo, y aquí nos basamos principalmente en lo acontecido en el suelo chileno de Magallanes -que tiene su correlato de semejanza en el argentino de Santa Cruz-, el sistema establecido contribuyó de manera eficaz a la seguridad y a la tranquilidad de cuantos habitaban en el ámbito rural, afirmación que no implica un juicio de valor sino simplemente la constatación de un hecho.

Aun apreciado el punto desde un punto de vista negativo para aquél como es la opinión del sociólogo Joaquín Bascopé que utiliza el concepto de "desierto biopolítico", que ciertamente no compartimos, en tanto cuanto afirma que fue un resultado deliberadamente buscado ${ }^{26}$, es posible comprobar cómo el deambular controlado de la gente en los campos una vez concluida la relación laboral entre los trabajadores y diferentes establecimientos pastoriles -los "pasajeros"27- ciertamente hizo posible tal realidad histórica.

26 Pasajeros del poder propietario. La Sociedad Explotadora de Tierra del Fuego y la biopolítica estanciera (1890-1920), Magallania, 36(2): 19-44. Punta Arenas 2008.

27 También han sido popularmente conocido como "tumberos", voz originada en las presas de carne ovina ("tumbas") que integran el puchero campesino patagónico. De allí, también, la forma verbal "tumbear" propia del habla magallánica para significar el caminar de un lado para otro sin motivo aparente.
Lo de "controlado" debe ser entendido en tanto cuanto tal deambular seminomádico fue regulado de hecho por una suerte de ley no escrita que normó la permanencia (días) en un lugar (sede principal de una estancia, secciones o puestos de la misma), con derechos (alimentación y/o alojamiento; forraje para los caballos y carne para los perros ovejeros) y las obligaciones en retribución (trabajos menores) que imponía el sistema. Con su funcionamiento que ha superado el siglo de vigencia, aunque muy atenuado por la evolución de las costumbres y la desaparición del antiguo sistema latifundario, se descomprimió el ambiente social rural y se evitó, está claro, el movimiento (circulación) de gente proclive al ocio en tanto que agente ocasional de mal vivir.

Por el contrario en el centro-occidente de la Patagonia el reparto de la tierra para la colonización se hizo, en general, bajo el sistema de la pequeña o mediana propiedad (o tenencia en su caso), circunstancia que de partida significó tener una población residente numerosa; si a ello se agrega el evidente atractivo natural de la zona precordillerana oriental y la relativa bondad climática, puede entenderse la facilidad de circulación por la misma de gente que podía o no tener relación con ella, máxime cuando, según parece, no había normas que la regularan a la manera que se hacía en el sur. ¿Pero, cabe preguntarse, hasta dónde la diferencia entre los sistemas de ocupación del suelo y las formas de producción económica y sus consecuencias, además de las características sociales que pudieron definir la tranquilidad pública en los correspondientes espacios geográficos pudo ser la razón condicionante de las distintas situaciones? y si no ¿cuáles otras razones habría que buscar en los órdenes moral y cultural para comprender lo históricamente acontecido en los ámbitos fronterizos de que se trata?

Aceptando la variedad en la apreciación, la que nos ocupa es una materia en donde los sociólogos y/o los antropólogos sociales tienen algo que decir para explicar tan curiosa diferencia de situaciones en lo referido a la seguridad de vida en los espacios fronterizos en la Patagonia durante el período del asentamiento colonizador y aun con posterioridad al mismo, como lo prueba el testimonio del ingeniero Pomar.

Es una situación que merece ser considerada. 




Fig. 1. Mapa esquemático que muestra la Patagonia en el período de entre siglos XIX/XX, con indicación de los ámbitos de interrelación fronteriza. A: espacio fronterizo Patagonia centro-occidental y B: Espacio fronterizo Patagonia austral. 


\section{AGRADECIMIENTOS}

El autor deja constancia de su reconocimiento hacia el señor Hugo Jankelevich Wortsman por sus informaciones sobre la permanencia familiar en el antiguo hotel rural de Ciaike a comienzos del siglo $\mathrm{XX}$. De igual modo hacia la Dra. Dominique Legoupil por su colaboración en el diseño del mapa que acompaña a este artículo y al Dr. Marcelo Gavirati por su lectura crítica del trabajo y comentarios.

\section{FUENTES DE CONSULTA}

a) Impresas

AguAdo, A. 2001. El viejo Oeste de la Patagonia. Lago Blanco-Valle Huemules- El Chalía - Chubut. Edición del autor. Comodoro Rivadavia.

BASCOPÉ, J. 2008. Pasajeros del poder propietario. La Sociedad Explotadora de Tierra del Fuego y la biopolítica estanciera (1890-1920). Magallania 36(2): 19-44. Punta Arenas.

CHILDS, H. 1997 (1936) El Jimmy, Bandido de la Patagonia. Ediciones de la Universidad de Magallanes, Punta Arenas.

CRAMER, J. A. 2006. Por si quede. Historias de pobladores y en el fogón contadas por ellos mismos. Photo Deisgn. Buenos Aires.

DIARIO "EL COMERCIO". Ediciones de los años 1905 a 1908. Punta Arenas.

FINKELSTEIN, D. Y M. M. NOVELLa 2002. Cruzando la cordillera con familia, animales y avíos. En Patagonia 1300 años de historia. Museo Leleque. Emece Editores. Buenos Aires.

FUENTES RABE, A. 1923. Tierra del Fuego. Valdivia.

GAVIRATI, M. 2002. Del "Lejano Oeste" norteamericano al "Lejano Sur" argentino. Inmigración norteamericana en la Patagonia. En Patagonia 1300 años de historia. Museo Leleque. Emece Editores. Buenos Aires.

2005. Buscados en la Patagonia. La historia no contada de Butch Cassidy y los bandoleros norteamericanos. Segunda edición ampliada y corregida. La Bitácora Patagónica- Patagonia Sur Libros. Buenos Aires.

MAGGIORI, E. 2004. Historia de Frontera. Policías, bandidos, baqueanos, arrieros, comerciantes, peones y troperos. Edición del autor. Comodoro Rivadavia.
MARTINIC, M. 1980. Patagonia de ayer y de hoy. Sociedad Difusora Patagonia. Punta Arenas.

1995. Los aónikenk. Historia y cultura. Edición de la Universidad de Magallanes. Punta Arenas.

2002 (1983). Ultima Esperanza en el tiempo. Edición de la Universidad de Magallanes. Punta Arenas.

2003. La minería aurífera en la Región Austral Americana. Historia 36: 219-254. Instituto de Historia, Pontificia Universidad Católica de Chile. Santiago.

2005. La hotelería en el antiguo Magallanes (1870-1950). Magallania 33(1): 5-24. Punta Arenas.

2006. El poblamiento rural en Magallanes durante el siglo XX. Realidad y utopía. Magallania 34(1): 5-20. Punta Arenas.

MARTINIC, M. Y D. S. CAMPBELL 2010. Las comisarías rurales del antiguo Territorio de Colonización de Magallanes (1902-1927). Magallania 38(1): 5-18. Punta Arenas.

MEADOWS, A. 1994. Digging up Butch and Sundance. St. Martin Press New York.

Pomar, J. M. 1923. La concesión de Aisén y el valle Simpson (notas y recuerdos de un viaje de inspección en Mayo y junio de 1920). Imprenta Cervantes. Santiago.

SEPIURKA, S. Y J. MIGLIOLLI 2004. Rocky Trip. La ruta de los galeses en la Patagonia. Consejo Federal de Investigaciones-Gobierno de la Provincia del Chubut. Buenos Aires.

TOPCIC, D. O. 2006: Historia de la Provincia de Santa Cruz. Crónicas y testimonios. Centro de Estudios Históricos "Prof. Carlos S. A. Segreti". Córdoba.

\section{b) Electrónicas}

JANKELEVICH WORTSMAN, H. E-mail: Hugojwortsman@ gmail.com. Comunicaciones de fecha de 18 y 20 de octubre, 4 de noviembre y 5 de diciembre de 2011, y del 23 de enero de 2012.

\section{c) Cartografía}

DONOSO, A. 1902. Planos Topográficos de la hijuelación de los terrenos fiscales en el Territorio de Magallanes. Escala 1:250.000. Santiago.

OFICINA DE MENSURA DE TIERRAS. Ministerio de Fomento. 1910. Mapa de Chile. Escala 1:500.000. Cuarterón 6530 Oeste / $51^{\circ}$ 53으. Sur. Santiago de Chile 